\title{
Proportion of Vitamin D Deficiency in Subjects with Excessive Day Time Sleepiness in a Tertiary Care Psychiatric setting in Thiruvananthapuram
}

\author{
Devika J. ${ }^{1}$, Arun B. Nair ${ }^{2}$ \\ ${ }^{1}$ Department of Physiology, Government Medical College, Konni, Kerala, India. ${ }^{2}$ Department of Psychiatry, \\ Government Medical College, Thiruvananthapuram, Kerala, India.
}

\section{ABSTRACT}

\section{BACKGROUND}

The role of vitamin D in normal human physiology has garnered a lot of discussions lately. It is now considered that Vitamin D exerts multiple effects beyond its role in bone physiology. Growing evidence suggests an association between hypovitaminosis D and sleep disorders, thus increasing the interest in the role of this vitamin in sleep. Vitamin D receptors have been found in the brain regions involved in sleep regulation, and vitamin D appears to be involved in regulating the sleep wake cycle. The study intended to explore the proportion of patients with excessive daytime sleepiness having vitamin D deficiency.

\section{METHODS}

This was a cross sectional study conducted in an urban primary care psychiatric clinic. The vitamin D levels of seventy-five patients who attended the clinic with complains of decreased sleep between the ages of 20 -75 years was collected. Their sleep score was assessed using Epsworth sleepiness scale and proportion with their vitamin D deficiency was analysed.

\section{RESULTS}

Of the 75 patients, 40 (53.3\%) were males and 35 (46.7\%) were females. The average vitamin $\mathrm{D}$ of the population was 16.62 with a standard deviation of 9.17 . (16.62 \pm 9.17). Of the analysed patients $13(17.3 \%)$ had severe vit D deficiency, 40 (53.3\%) had moderate deficiency and 19 (25.3\%) had mild deficiency. 3 (4\%) patients had normal vitamin D levels.

\section{CONCLUSIONS}

Vitamin D has both a direct and an indirect role in the regulation of sleep. Although vitamin D deficiency has been associated to sleep disorders, there is still scant evidence to concretely support the role of vitamin D supplementation in the prevention or treatment of sleep disturbances; indeed, more intervention studies and RCT are needed to better clarify these aspects.

\section{KEY WORDS}

Vitamin D, Deficiency, Sleep Disorders, Adults
Corresponding Author:

Dr. Arun B. Nair,

Associate Professor,

Department of Psychiatry,

Government Medical College,

Thiruvananthapuram, Kerala, India.

E-mail: devikaj2003@yahoo.co.in

DOI: $10.14260 / j e m d s / 2021 / 806$

How to Cite This Article:

Devika J, Nair AB. Proportion of Vitamin D deficiency in subjects with excessive day time sleepiness in a tertiary care psychiatric setting in Thiruvananthapuram. J Evolution Med Dent Sci 2021;10(45):3993-3997, DOI: 10.14260/jemds/2021/806

Submission 16-10-2021,

Peer Review 25-10-2021,

Acceptance 21-12-2021,

Published 29-12-2021.

Copyright (c) 2021 Devika J. et al. This is an open access article distributed under Creative Commons Attribution License [Attribution 4.0 International (CC BY 4.0)] 


\section{BACKGROUND}

Since the last few decades sleep disorders have emerged as a major health problem evolving into epidemic proportions worldwide.1,2,3,4 There is increasing evidence suggesting the possibility that the sleep disorders might be a cause for other lifestyle disorders like depression, cerebrovascular events, hypertension, diabetes, coronary artery diseases ${ }^{5}$ and chronic pain, which are now considered serious public health issues in the current era. Sleep is regulated by different regions of the brain, mainly the hypothalamus. A number of neurotransmitters in these different brain areas are involved in coordinating the sequential events of sleep onset to the timely progression of the different stages of sleep.

Vitamin D, which is a fat-soluble vitamin is also a prohormone having multiple actions on our body including calcium homeostasis ${ }^{6}$ and immunity. ${ }^{7,8}$ Calcitriol (1a, 25 $(\mathrm{OH})$ 2D), the active form is synthesised by the final hydroxylation in the kidneys. It binds to the vitamin $\mathrm{D}$ receptor (VDR), which also acts as a transcription factor that translocates to the cell nucleus. Inside the cell, in the nucleus it is heterodimerized with the retinoid $\mathrm{X}$ receptor (RXR). This calcitriol-VDR-RXR complex couples to a specific sequence of DNA known as the Vitamin D response element (VDRE), which is associated with promoters of several target genes and co-activator molecules. 9,10

An inadequate level of vitamin $\mathrm{D}$ has been linked to a number of diseases including metabolic disorders, ${ }^{11}$ psychiatric, respiratory and cardiovascular disorders, ${ }^{12}$ autoimmune conditions, and cancers as well as osteoporosis and osteomalacia.13,14 The presence of vitamin D receptors in most of the organs probably shows its involvement in all the diseases in these organ systems. ${ }^{15}$

In 2009, the National Health and Nutrition Examination Survey (NHANES) has shown that reduced vitamin D levels correlated with shorter sleep duration. ${ }^{16}$ As of 2019 around 12 studies had been published with varying results regarding association between serum vitamin D deficiency and poor sleep quality sleep duration. ${ }^{17,18,19}$ The impact of vitamin D on our brain is an ongoing research area. How exactly this molecule modifies the neural networks is yet to be found out.

Neurons in the brain where Vitamin D acts, has been located in several animals using radiolabelled 1,25 (OH)2 vitaminD3 and the sensitive receptor micro autoradiography method.20 16Vitamin D target cells are also present in the basal forebrain, the hypothalamic periventricular region (anterior hypothalamus), and preoptic-septal regions. It is strongly labelled in the reticular nucleus of thalamus. The current model of neurocircuitry of sleep suggests that a cluster of GABA and galaninergic neurons in the ventrolateral preoptic (VLPO) hypothalamus, a nucleus in anterior hypothalamus is selectively activated during the onset of sleep. ${ }^{21}$ This points towards the executive role in sleep regulation that the hypothalamic VLPO neurons play. Along with VLPO, the median preoptic nucleus (MnPOn), also in anterior hypothalamus, also shows similar activation patterns and projections, probably pointing towards a multicentre involvement for sleep onset and regulation. ${ }^{22}$ Sleep-promoting GABAergic nuclei are also isolated in the brainstem. It is now considered that stimulation of the anterior hypothalamus and the adjacent basal forebrain region causes sleep. ${ }^{23,24}$ The presence of vitamin D receptors and its activity close to these sleep promoting areas of brain might denote a prominent role of vitamin D in sleep onset.

The presence of receptors for vitamin $\mathrm{D}$ has also been detected in nucleus reticularis pontis oralis and caudalis which is considered to be involved in the onset of rapid eye movement (REM) sleep implies that some role in regarding REM sleep is contributed by vitamin D. ${ }^{25}$

Another factor to be noted is that the Vitamin D receptors seen in the periventricular brain and brainstem are closely associated with retinal projections to the supra chiasmatic nuclei. This points to its probable role in the the sleep/wake cycle by affecting the circadian clock mechanism. ${ }^{26} \mathrm{~A}$ endocrine-visceral optic pathway, different from the visual pathway has been detected in the tree shrew. It had projections from retina to the anterior hypothalamus, the anterodorsal thalamic nuclei, and the nucleus opticus ventralis of the medulla in addition to that to the suprachiasmatic nucleus. ${ }^{27}$ Therefore the role of hormonal systems which might act as an intricate feedback complex with the hypothalamus receiving cues from the internal and external environment and integrating this information in the medial basal diencephalon for the maintenance of circadian cycle in these animals becomes relevant. ${ }^{28,29}$ The role that vitamin D plays in controlling the production of melatonin, the pineal gland hormone regulating the circadian and the sleep cycle is now evident. It regulates tryptophan hydroxylases (TPH)-2,30 which converts tryptophan into 5hydroxytryptophan, which is metabolized to serotonin to produce the sleep hormone, melatonin. ${ }^{31}$

Insomnia is characterized by a difficulty in initiating and/or maintaining sleep or early awakening with a frequency of more than 3 times a week over a period of 3 months (ICSD-3, 2014), and affects around $15-45 \%$ of the general population. Individuals with insomnia frequently have a non-restorative sleep and may present early awakenings. Among the predisposing and risk factors are female gender, anxiety and depression. ${ }^{32}$

\section{Objective}

Our primary objective was to find out the proportion of subjects with excessive daytime sleepiness having vitamin D deficiency.

\section{METHODS}

This was a cross sectional study of subjects who came to an urban psychiatric clinic in Thiruvananthapuram during May 2018 to April 2019, with complaints of excessive daytime sleepiness. Informed consent for using the data was obtained before the study was started.

In patients who underwent an initial sleep medicine evaluation for sleep disorders, venous blood sampling for 250HD was done.

Patients above 20 years who reported with complaints of excessive daytime sleepiness and scored more than a score of 15 in Epsworth sleepiness scale were included.

All subjects who had taken vitamin D previously were excluded from the study. We also excluded patients who had thyroid diseases, hepatic or renal diseases, metabolic rickets, 
and any other medication that could influence vitamin D concentrations. We also excluded any patients diagnosed or currently undergoing treatment for anxiety, depression or psychotic illnesses.

Non-fasting venous blood samples were collected in tubes containing anticoagulant (EDTA - K2). Blood samples were stored at $4^{\circ} \mathrm{C}$ and analysed within 4 hours.

Micronutrient Status: Vitamin D was measured with electrochemiluminescence technique (Elecsys 2010, Roche Diagnostics, Mannheim, Germany).

Vitamin D insufficiency has been defined as a $25(\mathrm{OH}) \mathrm{D}$ of 21 - $29 \mathrm{ng} / \mathrm{ml}$. Deficiency of vitamin D was defined as vitamin D less than $20 \mathrm{ng} / \mathrm{ml}$. Severe Vitamin D deficiency has been defined as a $25(\mathrm{OH}) \mathrm{D}$ of less than $10 \mathrm{ng} / \mathrm{ml} .^{33}$

The patients were divided into 4 diagnostic categories according to their serum 250HD concentrations, as rounded to the nearest integer. In increasing order of severity, the 250HD levels were as follows: vitamin D insufficiency; vitamin D deficiency, severe vitamin D deficiency and normal vitamin D levels.

\section{Statistical Analysis}

Data management and data analysis was performed using SPSS (Statistical Package for the Social Sciences for Windows, IBM, Armonk, NY, USA) version 23.0. The nominal variables are presented as frequency and proportion.

\section{RESULTS}

\section{Age}

We included subjects in age group of 20 to 72 years. The mean age of the study population was $35.99+14.64$ years.

\section{Gender}

The study sample included 40 males (53.3 \%) and 35 females (46.7\%).

\begin{tabular}{|ccc|}
\hline & Frequency & Percent \\
Male & 40 & 53.3 \\
Female & 35 & 46.7 \\
Total & $\mathbf{7 5}$ & $\mathbf{1 0 0 . 0}$ \\
\hline Table 1. Distribution of Study Subjects Based on Gender \\
\hline
\end{tabular}

\section{Vitamin D Status}

The average vitamin D of the population was 16.62 with a standard deviation of 9.17. (16.62 \pm 9.17$)$.

\begin{tabular}{|ccc|}
\hline & Frequency & Percent \\
\hline Hypovitaminosis D & 72 & 96 \\
Normal & 3 & 4 \\
Total & $\mathbf{7 5}$ & $\mathbf{1 0 0 . 0}$ \\
\hline Table 2. Distribution of Study Subjects Based on Vitamin D Level \\
\hline
\end{tabular}

\begin{tabular}{|ccc|}
\hline Vitamin D Status & Frequency & Percentage \\
1)Insufficiency $(20-29 \mathrm{nd} / \mathrm{dl})$ & 13 & 17.3 \\
2)Deficiency $(<20 \mathrm{ng} / \mathrm{dl})$ & 40 & 53.3 \\
3)Severe deficiency $(<10 \mathrm{ng} / \mathrm{dl})$ & 19 & 25.3 \\
4)Normal $(>30 \mathrm{ng} / \mathrm{dl})$ & 3 & 4.1 \\
Total & $\mathbf{7 5}$ & $\mathbf{1 0 0}$ \\
\hline Table 3. Frequency Distribution of Vitamin D Insufficiency, Deficiency, \\
Severe Deficiency in Deficient Study Subjects \\
\hline
\end{tabular}

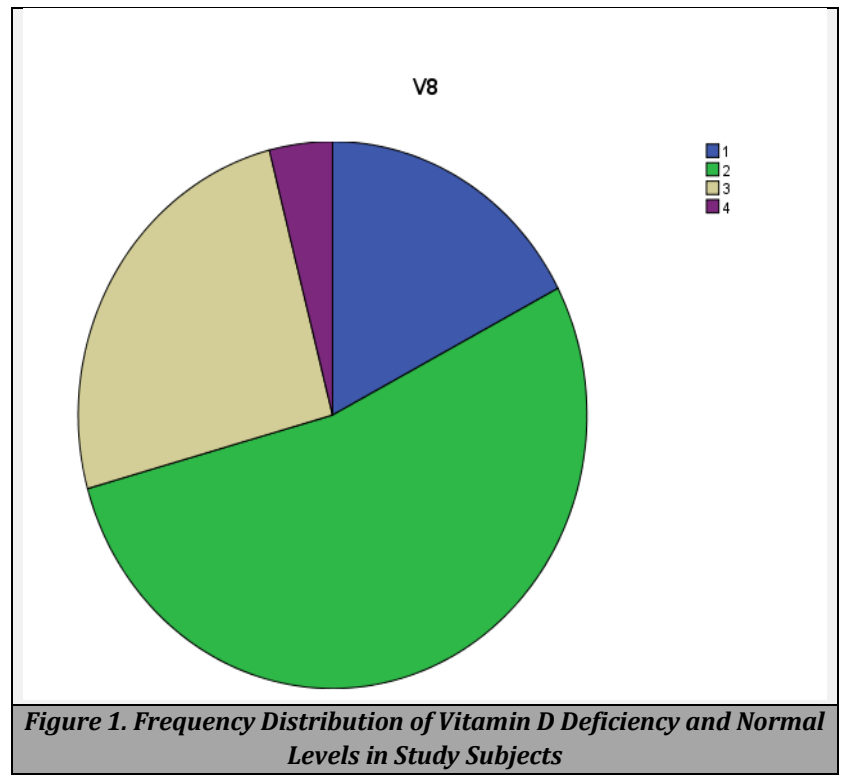

\section{DISCUSSION}

There is a definitive anatomic and epidemiological association between abnormalities in sleep and vitamin D deficiency. It is supported by the presence of vitamin D receptors in the anterior and posterior hypothalamus, substantia nigra, midbrain central gray, raphe nuclei, and the basal forebrain, the same areas which are considered to play a role in the initiation and maintenance of sleep. The hypothalamus, its associated projections, and the nucleus reticularis pontis appear to coordinate the sleep / wake state and the paralysis of the bulbar and somatic musculature during sleep. Pacemaker cells of the brainstem appear to play an important role in the timing of sleep. Vitamin D's effects on these brain areas may provide an explanation for seasonal variations in sleep seen in normal humans, as well as suggesting a treatable aetiology for the current epidemic of sleep disorders. ${ }^{34}$

Many conditions interfere with the endogenous synthesis of vitamin D such as low sun exposure, 35 race / ethnicity and skin color, ${ }^{36}$ season, altitude, and latitude. ${ }^{37}$

Our study revealed that a prominent number (96\%) of subjects suffering from excessive day time sleepiness showed an insufficiency of vitamin D. Of these a majority (53.3\%) had vitamin D values between $11 \mathrm{ng} / \mathrm{dl}$ to $20 \mathrm{ng} / \mathrm{dl}$, with a mean value of $16.6 \pm 9.1$.

Our study sample showed more males $(53.3 \%)$ had complaints of excessive daytime sleepiness compared to females. The average age of our study population was $36 \pm$ 14.6 years.

Future perspectives: vitamin D supplementation for sleep disorders. As evidenced by recent study vitamin D status seems to have an important role in the relationship between sleep onset and quality of sleep. A study evaluating the effects of cholecalciferol supplementation (1200 IU / day to individuals with serum 250HD between 20 and $29 \mathrm{ng} / \mathrm{mL}$ and 50,000 IU / weekly to those with serum 250HD < $20 \mathrm{ng} /$ $\mathrm{mL}$ ) in veterans with multiple areas of chronic pain found an improvement in sleep pattern, with decreased sleep latency and increased sleep duration. ${ }^{38}$ One challenge we might face 
while endorsing this supplementation is to establish the adequate dosage of vitamin $\mathrm{D}$ which will be difficult, owing to the seasonal, geographic, genetic and interracial variations in endogenous vitamin D synthesis. Secondly the adequate duration, especially in cases of other co morbidities also becomes difficult. An ideal solution in this problem might be to combine vitamin D supplementation with sleep hygiene to optimize the effects. Sleep hygiene consists of several interventions to improve sleep, i.e., changes in the habits that precede sleep, such as avoiding the consumption of alcoholic and caffeinated drinks; reducing lighting in the bedroom and use of electronic appliances; and maintaining regular sleep schedules. ${ }^{39}$

\section{CONCLUSIONS}

Sleep disorders have now become a relevant socioeconomic problem beyond a simple public health issue. It thus becomes important to find and promote adequate solution for reducing its impact on health resources and health economy ${ }^{4}$ Vitamin D could play a promising role in sleep disorders. Considering several limitations found in some meta-analysis studies, ${ }^{40}$ more data from RCTs is required to confirm the efficacy of vitamin D supplementation for improving sleep disorders.

Data sharing statement provided by the authors is available with the full text of this article at jemds.com.

Financial or other competing interests: None.

Disclosure forms provided by the authors are available with the full text of this article at jemds.com.

\section{REFERENCES}

[1] Halbower AC, Marcus CL. Sleep disorders in children. Curr Opin Pulm Med 2003;9(6):471-6.

[2] Van Cauter E, Spiegel K, Tasali E, et al. Metabolic consequences of sleep and sleep loss. Sleep Med 2008;9(Suppl 1):S23-8.

[3] Bonnet MH, Arand DL. We are chronically sleep deprived. Sleep 1995;18(10):908-11.

[4] Skaer TL, Sclar DA. Economic implications of sleep disorders. Pharmacoeconomics 2010;28(1):1015-23.

[5] Lurie A. Cardiovascular disorders associated with obstructive sleep apnea. Adv Cardiol 2011;46:197-266.

[6] Christakos S, Dhawan P, Liu Y, et al. New insights into the mechanisms of vitamin D action. J Cell Biochem 2003;88(4):695-705.

[7] Kamen DL, Vin T. Vitamin D and molecular actions on the immune system: modulation of innate and autoimmunity. J Mol Med 2010;88(5):441-50.

[8] Manolagas SC, Provvedini DM, Tsoukas CD. Interactions of 1,25-dihydroxyvitamin D3 and the immune system. Mol Cell Endocrinol 1985;43(2-3):113-22.

[9] Holick MF, Binkley NC, Bischoff-Ferrari HA, et al. Evaluation, treatment, and prevention of vitamin D deficiency: an Endocrine Society clinical practice guideline. J Clin Endocrinol Metab 2011;96(7):1911-30.

[10] Awada Z, Ossaily S, Zgheib N. The nutrigenetics and pharmacogenetics of vitamin $\mathrm{D}$ pathways. Curr
Pharmacogenomics Personalized Med (CPPM) 2014;12(2):89-103.

[11] Rajagopalan N. Obstructive sleep apnea: not just a sleep disorder. J Postgrad Med 2011;57(2):168-75.

[12] Bagai K. Obstructive sleep apnea, stroke and cardiovascular disease. Neurologist 2010;16(6):329-39.

[13] Grober U, Spitz J, Reichrath J, et al. Vitamin D: update 2013: from rickets prophylaxis to general preventive healthcare. Dermatoendocrinol 2013;5(3):331-47.

[14] Straube S, Moore RA, Derry S, et al. Vitamin D and chronic pain. Pain 2009;141(1-2):10-3.

[15] Adams JS, Hewison M. Update in vitamin D. J Clin Endocrinol Metab 2010;95(2):471-8.

[16] Pande RU, Chandrasekhar R, Kaplish N, et al. Low serum vitamin $\mathrm{D}$ concentration as a predictor of short sleep duration: a NHANES 2005-2006 analysis. Sleep 2009;32:A136.

[17] Bertisch SM, Sillau S, de Boer IH, et al. 25Hydroxyvitamin D concentration and sleep duration and continuity: multi-ethnic study of atherosclerosis. Sleep 2015;38(8):1305-11.

[18] Jennifer M, Stone KL, Wei EK, et al. Vitamin D and actigraphic sleep outcomes in older community-dwelling men: the MrOS sleep study. Sleep 2015;38(2):251-7.

[19] Muscogiuri G, Barrea L, Scannapieco M, et al. The lullaby of the sun: the role of vitamin $\mathrm{D}$ in sleep disturbance. Sleep Medicine 2019;54:262-5.

[20] Stumpf WE, Bidmon HJ, Li L, et al. Nuclear receptor sites for vitamin D-soltriol in midbrain and hindbrain of Siberian hamster (Phodopus sungorus) assessed by autoradiography. Histochemistry 1992;98(3):155-64.

[21] Nauta WJ. Hypothalamic regulation of sleep in rats; an experimental study. J Neurophysiol 1946;9:285-316.

[22] Sherin JE, Shiromani PJ, McCarley RW, et al. Activation of ventrolateral preoptic neurons during sleep. Science 1996;271(5246):216-9.

[23] Rechtschaffen A, Siegel J. Sleep and dreaming. Chap- 47. In: Kandel ER, Schwartz JH, Jessell TM, eds. Principles of neural science. $4^{\text {th }}$ edn. McGraw-Hill Medical 2000:93647.

[24] McGinty DJ, Sterman MB. Sleep suppression after basal forebrain lesions in the cat. Science 1968;160(3833):1253-5.

[25] Stumpf WE, O’Brien LP. 1,25 (OH)2 vitamin D3 sites of action in the brain. An autoradiographic study. Histochemistry 1987;87(5):383-406.

[26] Watts AG. The efferent projections of the suprachiasmatic nucleus: anatomic insight into the control of circadian rhythms. In: Klein DC, Moore RY, Reppert SM, eds. Suprachiasmatic nucleus. The mind's clock. New York: Oxford University Press 1991:77-106.

[27] Conrad CD, Stumpf WE. Endocrine-optic pathways to the hypothalamus. In: Stumpf WE, Grant LD, eds. Anatomic neuroendocrinology. Kargers: Basel 1975:15-29.

[28] Dibner C, Schibler U, Albrecht U. The mammalian circadian timing system: organization and coordination of central and peripheral clocks. Annu Rev Physiol 2010;72:517-49.

[29] Musiol IM, Stumpf WE, Bidmon HJ, et al. Vitamin Dnuclear binding to neurons of the septal, substriatal, and amygdaloid area in the siberian hamster (Phodopus sungorus) brain. Neuroscience 1992;48(4):841-8. 
[30] Kaneko I, Sabir MS, Dussik CM, et al. 1,25Dihydroxyvitamin D regulates expression of the tryptophan hydroxylase 2 and leptin genes: implication for behavioral influences of vitamin D. FASEB J 2015;29(9):4023-35.

[31] Patrick RP, Ames BN. Vitamin D and the omega-3 fatty acids control serotonin synthesis and action, part 2: relevance for ADHD, bipolar disorder, schizophrenia, and impulsive behavior. FASEB J 2015;29(6):2207-22.

[32] Castro LS, Poyares D, Leger D, et al. Objective prevalence of insomnia in the São Paulo, Brazil epidemiologic sleep study. Ann Neurol 2013;74(4):537-46.

[33] Amrein K, Scherkl M, Hoffmann M, et al. Vitamin D deficiency 2.0: an update on the current status worldwide. Eur J Clin Nutr 2020;74:1498-513.

[34] Gominak SC, Stumpf WE. The world epidemic of sleep disorders is linked to vitamin D deficiency. Med Hypotheses 2012;79(2):132-5.
[35] Holick MF, Chen TC. Vitamin D deficiency: a worldwide problem with health consequences. Am J Clin Nutr 2008;87(4):1080-6.

[36] McCarty DE, Reddy A, Keigley Q, et al. Vitamin D, race, and excessive daytime sleepiness. J Clin Sleep Med 2012;8(6):693-7.

[37] Moan J, Porojnicu AC, Dahlback A, et al. Addressing the health benefits and risks, involving vitamin $D$ or skin cancer, of increased sun exposure. Proc Natl Acad Sci U S A 2008;105(2):668-73.

[38] Huang W, Shah S, Long Q, et al. Improvement of pain, sleep, and quality of life in chronic pain patients with vitamin D supplementation. Clin J Pain 2013;29(4):3417.

[39] De Oliveira DL, Hirotsu C, Tufik S, et al. The interfaces between vitamin $\mathrm{D}$, sleep and pain. J Endocrinol 2017;234(1):R23-36.

[40] Yan S, Tian Z, Zhao H, et al. A meta-analysis: does vitamin D play a promising role in sleep disorders? Food Sci Nutr 2020;8(10):5696-709. 